\title{
Response to the letter: Is there a higher cardiovascular disease risk in Japanese-Brazilians?
}

\author{
Resposta à carta: Há um risco maior de doença \\ cardiovascular em nipo-brasileiros?
}

Patricia Moreira Gomes', Milton César Foss' ', Maria Cristina Foss-Freitas'

1 Department of Internal Medicine, Ribeirão Preto Medical School, Universidade de São Paulo (FMRPUSP), Ribeirão Preto, SP, Brazil

Correspondence to: Patricia.moreira@gmail.com

Received on Mar/13/2013 Accepted on Mar/21/2013
$\mathrm{O}$ ur study entitled "Cardiovascular risk in Japanese-Brazilian subjects" (1) aimed to assess which risk factors for cardiovascular disease, among those already well-established, such as diabetes, hypertension, dyslipidemia, and central obesity, were present in this Japanese-Brazilians population.

At the time of the study design (2005), waist circumference measurement was chosen as the marker of central obesity since it is simple, costless, and easily performed in the field study. It had also been validated in several studies. Additionally, waist circumference data is one of the criteria for the diagnosis of metabolic syndrome. Thus, we have no data on hip circumference to calculate BAI (2).

However, we made a brief analysis of our data using the waist/height index, as suggested by Kurt and cols. (3). We found that the WHtR index values in the general population ranged from 0.35 to 0.73 , with a mean of 0.54 and median of 0.52 . Regarding the women group, WHtR values were similar to the general population ( 0.35 to 0.73 ), while for men the index varied from 0.43 to 0.67 . Therefore, $51.4 \%$ of women and $52.8 \%$ of men showed the index between 0.5 and 0.59 , and $25.7 \%$ of women and $14.5 \%$ of men showed a rate higher than 0.6 . As the optimal cutoff points for WHtR were close to 0.5 in East Asians, and 0.6 in some ethnic groups, WHtR of 0.5 for action level one for cardiovascular risk, and 0.6 for action level two, as suggested by Ashwell and Hsieh, could be adopted.

The meta-analysis (3) involved Asians living in their countries of origin, and did not provide enough data on subject living in the Western world. In our study, people were either born in Japan or were of Japanese descent. Comparing our study with others conducted in Japan, our data showed increased rates for the components of Metabolic Syndrome in the Japanese-Brazilian population of Mumbuca.

We appreciate the suggestions of Kurt and cols., which will be remembered in a reassessment of the prevalence risk factors for cardiovascular disease in the JapaneseBrazilian population of Mombuca. Surely, BAI and waist/hip index assessment may contribute to better evaluation of cardiovascular risk in this population, and increase the discussion on which tools may be useful in clinical practice.

\section{REFERENCES}

1. Gomes PM, Andrade RCG, Figueiredo RC, Pace AE, Fabbro AL, et al. Cardiovascular risk in JapaneseBrazilian subjects. Arq Bras Endocrinol Metab. 2012;56:608-13.

2. Bergman RN. A better index of body adiposity. Obesity (Silver Spring, Md.). 2012;20:1135.

3. Lee CMY, Huxley RR, Wildman RP, Woodward M. Indices of abdominal obesity are better discriminators of cardiovascular risk factors than BMI: a meta-analysis. J Clin Epidemiol. 2008;61:646-53. 